\title{
$\mathrm{Cs}_{2} \mathrm{ZnSn}_{3} \mathrm{~S}_{8}$ : A sulfide compound realizes large birefringence by modulating the dimensional structure
}

AUTHOR NAMES. Tian Tian, *a Zefen Li, ${ }^{a}$ Naizheng Wang, ${ }^{c, d}$ Sangen Zhao, ${ }^{e}$ Jiayue Xu, ${ }^{a}$ Zheshuai Lin, ${ }^{c, d}$ Dajiang Mei $*, b, f$

\section{AUTHOR ADDRESS.}

${ }^{a}$ Institute of Crystal Growth, School of Materials Science and Engineering, Shanghai Institute of Technology, Shanghai 201418, China

${ }^{\mathrm{b}}$ College of Chemistry and Chemical Engineering, Shanghai University of Engineering Science, Shanghai 201620, China

${ }^{\mathrm{c}}$ Technical Institute of Physics and Chemistry, Chinese Academy of Sciences, Beijing 100190, China

${ }^{\mathrm{d}}$ University of Chinese Academy of Sciences, Beijing 100049, China

${ }^{\mathrm{e}}$ Key Laboratory of Optoelectronic Materials Chemistry and Physics and II State Key Laboratory of Structural Chemistry, Fujian Institute of Research on the Structure of Matter, Chinese Academy of Sciences, Fuzhou 350000, China

${ }^{\mathrm{f}}$ State Key Laboratory of Crystal Materials and Institute of Crystal Materials, Shandong University, Jinan 250100, China

*E-mail: tiant@sit.edu.cn.

*E-mail: meidajiang718@pku.edu.cn. 


\section{Contents}

\section{Experimental section and calculation.}

Table S1. Crystallographic data and refinement details of $\mathrm{Cs}_{2} \mathrm{ZnSn}_{3} \mathrm{~S}_{8}$.

Table S2. Selected bond lengths $(\AA)$ and angles (deg) of $\mathrm{Cs}_{2} \mathrm{ZnSn}_{3} \mathrm{~S}_{8}$.

Figure S1. The experimental and simulated X-ray diffraction results of $\mathrm{Cs}_{2} \mathrm{ZnSn}_{3} \mathrm{~S}_{8}$ powder.

Figure S2. Diffuse reflectance spectra of $\mathrm{Cs}_{2} \mathrm{ZnSn}_{3} \mathrm{~S}_{8}$.

Figure S3. Electronic band structure of $\mathrm{Cs}_{2} \mathrm{ZnSn}_{3} \mathrm{~S}_{8}$.

Figure S4. EDS analyses of $\mathrm{Cs}_{2} \mathrm{ZnSn}_{3} \mathrm{~S}_{8}$. 


\section{Solid State Syntheses.}

$\mathrm{Cs}_{2} \mathrm{~S}_{3}$ was synthesized by $\mathrm{Cs}$ and $\mathrm{S}$ with the method of liquid ammonia. $\mathrm{Cs}_{2} \mathrm{ZnSn}_{3} \mathrm{~S}_{8}$ was mixed with $\mathrm{Cs}_{2} \mathrm{~S}_{3}, \mathrm{Zn}, \mathrm{Sn}, \mathrm{S}$ in a certain proportion. Grind the reagents in a nitrogen-filled glove box, mix them evenly, put them into a carbon-coated quartz tube, and then sealed in quartz tube under vacuum. Heating for 4 days, the highest temperature was $800^{\circ} \mathrm{C}$, then cooled to $300^{\circ} \mathrm{C}$ at a rate of $8^{\circ} \mathrm{C} / \mathrm{h}$, finally cooled to room temperature naturally.

\section{Single crystal growth.}

The synthesized sample was ground evenly and put into a carbon-coated quartz tube, seal it under vacuum, and put it into a muffle furnace to set the temperature. Heating for 4 days, the highest temperature was $800^{\circ} \mathrm{C}$, then cooled to $300^{\circ} \mathrm{C}$ at a rate of $4^{\circ} \mathrm{C} / \mathrm{h}$, and finally cooling to room temperature naturally. Cleaning the sample to obtain crystals that was stable in the air.

\section{Powder X-ray diffraction.}

Taking out the sample and grind into powder, diffraction data of $\mathrm{Cs}_{2} \mathrm{ZnSn}_{3} \mathrm{~S}_{8}$ were measured and collected by Bruker X-ray diffractometer $(\lambda=1.5418 \AA)$ equipped with graphite to monochromatic $\mathrm{Cu} \mathrm{K} \alpha$ radiation at room temperature. The scanning range of $2 \theta$ was $10-70^{\circ}$, and the scanning step size was $0.02^{\circ}$. A comparison of the experimental and simulated X-ray diffraction data for $\mathrm{Cs}_{2} \mathrm{ZnSn}_{3} \mathrm{~S}_{8}$ was shown in Figure S1.

\section{Structure determination.}

A high-quality single crystal was selected from powder, the crystal 
structure data of $\mathrm{Cs}_{2} \mathrm{ZnSn}_{3} \mathrm{~S}_{8}$ was collected on a Rigaku AFC10 single crystal diffractometer using Mo $\mathrm{K} \alpha$ radiation. The crystal structure was solved by direct methods in SHELXTL system and the structure was refined by least squares method to check for missing structures. ${ }^{1}$ The crystal structure parameters were shown in Table S1, and the selected bond lengths and angles were shown in Table S2.

\section{UV-Vis diffuse reflectance spectroscopy analysis.}

The UV-Vis diffuse reflectance spectra of $\mathrm{Cs}_{2} \mathrm{ZnSn}_{3} \mathrm{~S}_{8}$ powder were collected from 200 to $1200 \mathrm{~nm}$ using a Shimadzu UV-3600 spectrophotometer with $\mathrm{BaSO}_{4}$ as a standard. The diffuse reflectance spectrum was analyzed using the up-cut method which was a common technique to determine the band gap of crystal. ${ }^{2}$ As presented in the inset of Figure S2, the band gap of $\mathrm{Cs}_{2} \mathrm{ZnSn}_{3} \mathrm{~S}_{8}$ was measured to be $3.20 \mathrm{eV}$. Meanwhile, the band gap was also obtained by Tauc's function (1): ${ }^{3-6}$

$$
(a h v)^{n}=A\left(h v-E_{g}\right)
$$

where $A$ is the absorption constant, $h$ is Planck's constant, $v$ is the light frequency, $E_{g}$ is the optical band gap, $n$ is a constant exponent that determines the type of optical transitions. $n$ equals to $1 / 2$ and 2 for indirect and direct allowed transitions, respectively. $\alpha$ is the absorption coefficient and is proportional to $F(R)$. Based on the UV-vis-NIR diffuse-reflectance spectrum, absorption $(F(R))$ data were calculated from the following Kubelka-Munk function (2): ${ }^{4-6}$ 


$$
F(R)=\frac{K}{S}=\frac{(1-R)^{2}}{2 R}
$$

where $R$ is the reflectance, $K$ is the absorption, and $S$ is the scattering.

\section{Birefringence Measurements.}

The birefringence of $\mathrm{Cs}_{2} \mathrm{ZnSn}_{3} \mathrm{~S}_{8}$ was characterized by using the polarizing microscope equipped (ZEISS Axio Scope. A1) with Berek compensator. The wavelength of the light source was $546 \mathrm{~nm}$. In order to improve the accuracy of birefringence, we chosen the small and transparent $\mathrm{Cs}_{2} \mathrm{ZnSn}_{3} \mathrm{~S}_{8}$ lamellar crystal.

\section{Theoretical calculations.}

The first-principles electronic structure calculation of $\mathrm{Cs}_{2} \mathrm{ZnSn}_{3} \mathrm{~S}_{8}$ was performed by $\mathrm{CASTEP}^{7}$ a total energy package based on plane-wave pseudopotential density functional theory (DFT). ${ }^{8-9}$ The exchangecorrelation (XC) functionals were described by the local density approximation (LDA). The effective interaction between the atomic cores and valence electrons were modeled by optimized norm-conserving pseudopotentials. ${ }^{10}$ In this mode, Cs $5 s^{2} 5 p^{6}, \mathrm{Zn} 3 d^{10} 4 s^{2}, \mathrm{Sn} 5 s^{2} 5 p^{2}$ and $\mathrm{S}$ $3 s^{2} 3 p^{4}$ were thread as valence electrons, such calculation parameters could allow small plane-wave basis set while ensuring calculation accuracy. The kinetic energy cutoff of $660 \mathrm{eV}$ and intensive Monkhorst-Pack ${ }^{11}$ k-point meshes spanning less than $0.04 / \AA^{3}$ were chosen. For the optical property calculations, the Perdew-Burke-Emzerhof $(\mathrm{PBE})^{12}$ functional within the framework of generalized gradient approximation (GGA) ${ }^{13}$ were chosen to 
discript the exchange-correlation functional. The convergence test showed that the calculation result was less than the allowable error and the above computational parameters were accurate enough for the purpose of this study.

\section{Elemental Analysis.}

Elemental analysis of the crystal was performed on ZEISS Gemini 300 SEM instrument equipped with an energy-dispersive spectrometry detector, and the result showed that the elemental composition of the crystal was Cs, Zn, Sn and S (Figure S4). 
Table S1. Crystallographic data and refinement details of $\mathrm{Cs}_{2} \mathrm{ZnSn}_{3} \mathrm{~S}_{8}$.

\begin{tabular}{|c|c|}
\hline Formula & $\mathrm{Cs}_{2} \mathrm{ZnSn}_{3} \mathrm{~S}_{8}$ \\
\hline Formula weight & 943.74 \\
\hline Crystal system & Monoclinic \\
\hline Space-group & $P 2_{1} / \mathrm{n}$ \\
\hline $\mathrm{a}(\AA)$ & $7.5366(2)$ \\
\hline $\mathrm{b}(\AA)$ & $17.6947(5)$ \\
\hline$c(\AA)$ & $12.4976(4)$ \\
\hline$\alpha\left(^{\circ}\right)$ & 90 \\
\hline$\beta\left(^{\circ}\right)$ & 94.830 \\
\hline$\gamma\left(\left(^{\circ}\right)\right.$ & 90 \\
\hline Volume $\left(\AA^{3}\right)$ & $1660.73(8)$ \\
\hline Z & 4 \\
\hline \multirow[t]{3}{*}{ Index ranges } & $-8<=\mathrm{h}<=8$ \\
\hline & $-21<=\mathrm{k}<=20$ \\
\hline & $-14<=1<=14$ \\
\hline $\mathrm{F}(000)$ & 1672 \\
\hline$\rho_{\mathrm{c}}\left(\mathrm{Mg} / \mathrm{m}^{-3}\right)$ & 3.775 \\
\hline$\mu\left(\mathrm{mm}^{-1}\right)$ & 11.177 \\
\hline $\mathrm{R}(\mathrm{F})^{\mathrm{a}}$ & 0.0202 \\
\hline $\operatorname{Rw}\left(\mathrm{Fo}^{2}\right)^{\mathrm{b}}$ & 0.0726 \\
\hline
\end{tabular}


Table S2. Selected bond lengths $(\AA)$ and angles (deg) of $\mathrm{Cs}_{2} \mathrm{ZnSn}_{3} \mathrm{~S}_{8}$.

\begin{tabular}{ll}
\hline $\mathrm{Zn}(1)-\mathrm{S}(4)$ & $2.3489(15)$ \\
$\mathrm{Zn}(1)-\mathrm{S}(1) \# 8$ & $2.3535(15)$ \\
$\mathrm{Zn}(1)-\mathrm{S}(8) \# 9$ & $2.3566(15)$ \\
$\mathrm{Zn}(1)-\mathrm{S}(7)$ & $2.3673(15)$ \\
$\mathrm{Sn}(1)-\mathrm{S}(7)$ & $2.3304(14)$ \\
$\mathrm{Sn}(1)-\mathrm{S}(2)$ & $2.3961(14)$ \\
$\mathrm{Sn}(1)-\mathrm{S}(3)$ & $2.4280(15)$ \\
$\mathrm{Sn}(1)-\mathrm{S}(5)$ & $2.4556(13)$ \\
$\mathrm{S}(4)-\mathrm{Zn}(1)-\mathrm{S}(1) \# 8$ & $104.41(5)$ \\
$\mathrm{S}(4)-\mathrm{Zn}(1)-\mathrm{S}(8) \# 9$ & $114.10(5)$ \\
$\mathrm{S}(1) \# 8-\mathrm{Zn}(1)-\mathrm{S}(8) \# 9$ & $109.17(5)$ \\
$\mathrm{S}(4)-\mathrm{Zn}(1)-\mathrm{S}(7)$ & $107.87(5)$ \\
$\mathrm{S}(1) \# 8-\mathrm{Zn}(1)-\mathrm{S}(7)$ & $109.30(5)$ \\
$\mathrm{S}(8) \# 9-\mathrm{Zn}(1)-\mathrm{S}(7)$ & $111.67(6)$ \\
$\mathrm{S}(7)-\mathrm{Sn}(1)-\mathrm{S}(2)$ & $117.74(6)$ \\
$\mathrm{S}(7)-\mathrm{Sn}(1)-\mathrm{S}(3)$ & $118.98(6)$ \\
$\mathrm{S}(2)-\mathrm{Sn}(1)-\mathrm{S}(3)$ & $111.40(5)$ \\
$\mathrm{S}(7)-\mathrm{Sn}(1)-\mathrm{S}(5)$ & \\
$\mathrm{S}(2)-\mathrm{Sn}(1)-\mathrm{S}(5)$ & \\
$\mathrm{S}(3)-\mathrm{Sn}(1)-\mathrm{S}(5)$ & \\
\hline
\end{tabular}




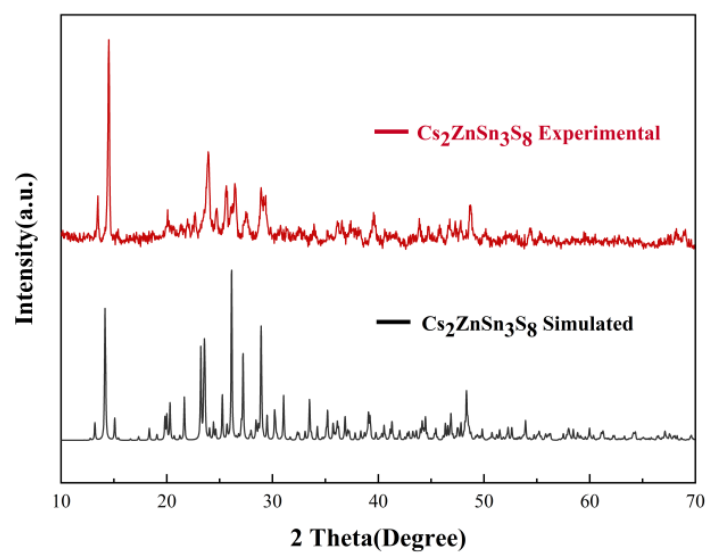

Figure S1. The experimental and simulated X-ray diffraction result of $\mathrm{Cs}_{2} \mathrm{ZnSn}_{3} \mathrm{~S}_{8}$ powder.

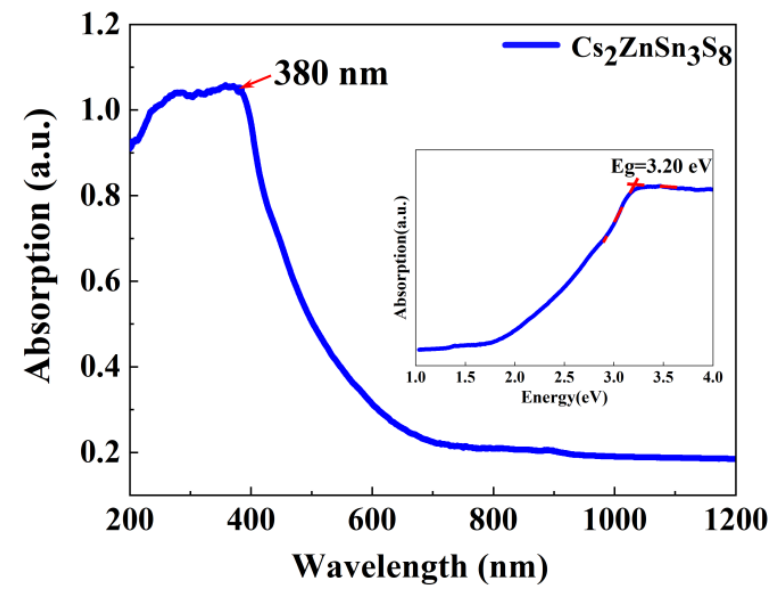

Figure S2. Diffuse reflectance spectra of $\mathrm{Cs}_{2} \mathrm{ZnSn}_{3} \mathrm{~S}_{8}$.

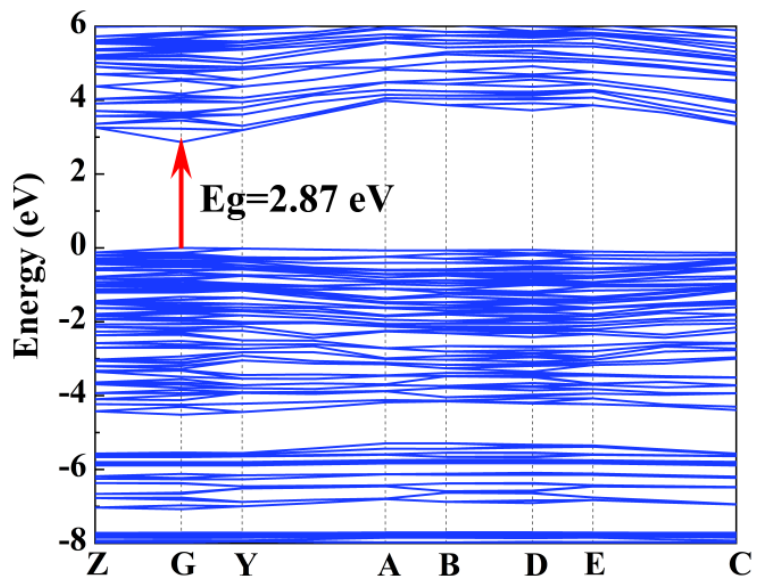

Figure S3. Electronic band structure of $\mathrm{Cs}_{2} \mathrm{ZnSn}_{3} \mathrm{~S}_{8}$. 


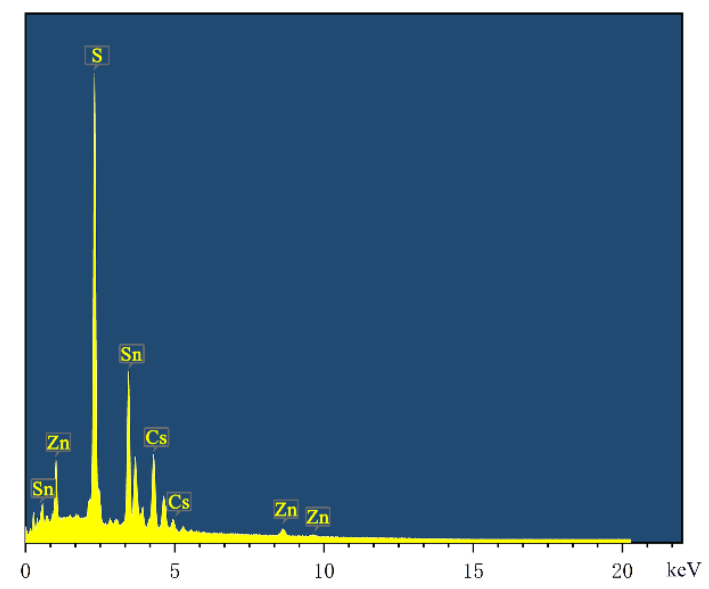

Figure S4. EDS analyses of $\mathrm{Cs}_{2} \mathrm{ZnSn}_{3} \mathrm{~S}_{8}$.

\section{REFERENCES.}

(1) Sheldrick, G. M. A short history of SHELX. Acta Crystallogr A. 2008, $64,112-122$.

(2) Mei, D. J.; Jiang, J. Q.; Liang, F.; Zhang, S. Y.; Wu, Y. D.; Sun, C. T.; Xue, D. F.; Lin Z. S. Design and synthesis of a nonlinear optical material $\mathrm{BaAl}_{4} \mathrm{~S}_{7}$ with a wide band gap inspired from $\mathrm{SrB}_{4} \mathrm{O}_{7}$. J. Mater. Chem. C. 2018, 6, 2684-2689.

(3) Tauc, J.; Grigorovici, R.; Vancu, A. Optical Properties and Electronic Structure of Amorphous Germanium. Phys. Stat. Sol. 1966, 15, 627-637.

(4) Brant, J. A.; Clark, D. J.; Kim, Y. S.; Jang, J. I.; Zhang, J. H.; Aitken, J. A. $\mathrm{Li}_{2} \mathrm{CdGeS}_{4}, \mathrm{~A}$ Diamond-Like Semiconductor with Strong Second-Order Optical Nonlinearity in the Infrared and Exceptional Laser Damage Threshold. Chem. Mater. 2014, 26, 3045-3048.

(5) Zhang, J. H.; Clark, D. J.; Brant, J. A.; Rosmus, K. A.; Grima, P.; Lekse, J. W.; Jang, J. I.; Aitken, J. A. $\alpha-\mathrm{Li}_{2} \mathrm{ZnGeS}_{4}$ : A Wide-Bandgap Diamondlike Semiconductor with Excellent Balance between Laser-Induced 
Damage Threshold and Second Harmonic Generation Response. Chem. Mater. 2020, 32, 8947-8955.

(6) Li, X. S.; Kang, L.; Li, C.; Lin, Z. S.; Yao, J. Y.; Wu, Y. C. PbGa $\mathrm{S}_{7}$ : a wide-gap nonlinear optical material. J. Mater. Chem. C. 2015, 3, 30603067.

(7) Clark, S. J.; Segall, M. D.; Pickard, C. J.; Hasnip, P. J.; Probert, M. I. J.; Refson, K.; Payne, M. C. First principles methods using CASTEP. Z. Krist-Cryst. Mater. 2005, 220, 567-570.

(8) Kohn, W.; Sham, L. J. Self-Consistent Equations Including Exchange and Correlation Effects. Phys. Rev. 1965, 140, A1133-A1138.

(9) Payne, M. C.; Teter, M. P.; Allan, D. C.; Arias, T. A.; Joannopoulos, J. D. Iterative minimization techniques forab initiototal-energy calculations: molecular dynamics and conjugate gradients. Rev. Mod. Phys. 1992, 64, 1045-1097.

(10) Hamann, D. R.; Schlüter, M.; Chiang, C. Norm-Conserving Pseudopotentials. Phys. Rev. Lett. 1979, 43, 1494-1497.

(11) Monkhorst, H. J.; Pack, J. D. Special points for Brillouin-zone integrations. Phys. Rev. B. 1976, 13, 5188-5192.

(12) Perdew, J. P.; Wang, Y. Accurate and simple analytic representation of the electron-gas correlation energy. Phys. Rev. B. 1992, 45, 13244-13249. (13) Perdew, J. P.; Burke, K.; Ernzerhof, M. Generalized Gradient Approximation Made Simple. Phys. Rev. Lett. 1996, 77, 3865-3868. 